\title{
Características fermentativas e químicas de silagens de capim-marandu produzidas com quatro pressões de compactação ${ }^{1}$
}

\section{Rafael Camargo do Amaral ${ }^{2}$, Thiago Fernandes Bernardes ${ }^{3}$, Gustavo Rezende Siqueira ${ }^{4}$, Ricardo Andrade Reis ${ }^{5}$}

\author{
1 Projeto financiado pela FAPESP. \\ ${ }^{2}$ Mestrando em Ciência Animal e Pastagens - ESALQ/USP \\ 3 Pós-Doutorando - ESALQ/USP. Bolsista FAPESP. \\ ${ }^{4}$ APTA Colina e Doutorando em Zootecnia FCAV/UNESP \\ ${ }^{5}$ Departamento de Zootecnia FCAV/UNESP. Pesquisador do CNPq.
}

RESUMO - Objetivou-se estudar silagens de capim-marandu (Brachiaria brizantha) produzidas com quatro pressões de compactação $\left(100,120,140\right.$ e $\left.160 \mathrm{~kg} \mathrm{MS} . \mathrm{m}^{-3}\right)$ durante a ensilagem. A forrageira foi colhida com 60 dias de crescimento vegetativo (32\% de MS). O delineamento experimental utilizado foi o inteiramente casualizado com quatro repetições. Os dados relativos à produção de gás foram analisados por meio do modelo de medidas repetidas no tempo. As silagens produzidas com menores pressões de compactação apresentaram maior intensidade de produção de gases. Em todos os tratamentos, houve baixa produção de efluente, como conseqüência do alto teor de MS da forragem no momento do corte. Nas maiores pressões de compactação, houve maior preservação dos teores de MS das silagens. Os valores de pH das silagens mais bem compactadas foram reduzidos em comparação aos daquelas com menor compactação, indicando que a maior densidade promoveu melhor ambiente para as bactérias produtoras de ácido lático. Os teores de $\mathrm{N}-\mathrm{NH}_{3}(\% \mathrm{~N}$ total) das silagens não foram influenciados pelas pressões de compactação durante a ensilagem; os resultados foram próximos aos considerados satisfatórios para conservação de gramíneas tropicais. A maior intensificação na compactação promoveu decréscimo nos valores de NIDN, fração B3, FDN e FDA e aumento na recuperação de MS e na digestibilidade verdadeira in vitro da MS.

Palavras-chave: Brachiaria brizantha cv. Marandu, ensilagem, fermentação, gramínea tropical, perdas

\section{Fermentative and chemical characteristics of marandugrass silage submitted to four compaction pressures}

\begin{abstract}
The objective of this experiment was to evaluate the fermentative and chemical parameters of four different bulk densities of marandugrass (Brachiaria brizantha) silages. The forage was harvested with 60 days of vegetative growth and $32 \%$ of DM. The bulk densities used were $100,120,140$ and $160 \mathrm{~kg} \mathrm{DM} / \mathrm{m}^{3}$. Treatments were distributed in a completely randomized design with four replicates. Gas production data were analyzed by repeated measures model. The lower density silages showed greater gas production. Low effluent production was observed in all treatments due to the high forage DM during harvesting. Higher bulk density silos showed lower DM losses and also achieved a lower pH than lower density silos. Ammoniacal nitrogen concentration was not influenced by treatments and the observed values were satisfactory for tropical grasses silages. Bulk density increase provided a reduction in NIDN, B3 fraction, NDF and ADF concentration. Higher bulk densities also provided greater DM recovery and greater true in vitro DM digestibility.
\end{abstract}

Key Words: Brachiaria brizantha cv. Marandu, ensilage, fermentation, losses, tropical grass

\section{Introdução}

A prática de ensilagem no Brasil foi iniciada no final do século XIX. Em 1935, trabalhos com silagens de gramíneas tropicais começaram a ser realizados, no entanto, sua intensificação ocorreu somente na década de 70, principalmente com o capim-elefante (Pennisetum purpureum Schum. cv. Napier) (Nussio et al., 2002).
Balsalobre et al. (2001) reportaram que o provável motivo do não uso de silagens de gramíneas tropicais até recentemente parece ter sido a falta de máquinas apropriadas para o corte das plantas de alto potencial de produção. Entretanto, nos últimos 15 anos, algumas empresas nacionais passaram a desenvolver e confeccionar equipamentos de maior capacidade operacional, o que tem viabilizado o uso de silagens em maior escala. 
O potencial da espécie forrageira para ensilagem depende de seu teor de água e carboidratos solúveis e de seu poder tampão no momento do corte (McDonald et al., 1991; Reis \& Coan, 2001). Essas características definem o tipo de fermentação ao qual a forragem será submetida e a qualidade da conservação da massa ensilada, que constitui o principal entrave na confecção de silagem de gramíneas tropicais de boa qualidade, visto que estas espécies, no ponto ideal de corte, possuem alto teor de umidade, alto poder tampão e baixo valor de carboidratos solúveis, o que prejudica a fermentação e impede a redução do $\mathrm{pH}$, depreciando o valor nutritivo do alimento (Woolford, 1984).

No processo de ensilagem, para obtenção de fermentação satisfatória, primeiramente é necessária a anaerobiose dentro do silo, resultante da efetiva homogeneidade do material picado, facilitando a compactação e, conseqüentemente, promovendo a expulsão do ar contido entre os poros do material. Segundo Muck et al. (2003), altas densidades promovem a eliminação do oxigênio e garantem condições de anaerobiose, além de reduzir o custo de estocagem da forragem, haja vista a amortização da estrutura e a redução das perdas por deterioração.

Entre os fatores que interferem na densidade da forragem ensilada, destacam-se o peso e a pressão de compactação, o tempo de compactação, a espessura da camada de forragem adicionada ao silo, a taxa de enchimento do silo, o teor de MS e o tamanho de partícula do material (Ruppel et al., 1995; Holmes \& Muck, 1999). Ruppel et al. (1995) avaliaram o manejo da produção de silagens de milho em 12 fazendas no estado de Nova York (EUA) e verificaram que o peso e o tempo utilizado na compactação, entre os parâmetros avaliados, foram os que melhor se correlacionaram às variações nas densidades das silagens. Segundo esses autores, o peso do equipamento deve ser de $40 \%$ do peso da forragem transportada por hora e a espessura da camada no silo deve ser de 15 a $30 \mathrm{~cm}$.

Igarasi (2002), realizando levantamento de índices técnicos associados à produção de silagens de capins tropicais, em que a densidade média das silagens de Panicum e Brachiaria foi de $142 \mathrm{~kg} \mathrm{MS}^{-3} \mathrm{~m}^{-3}$ e a amplitude, de 87 a $230 \mathrm{~kg} \mathrm{MS.m}{ }^{-3}$, constatou que $93 \%$ das amostras apresentaram densidade inferior a $200 \mathrm{~kg} \mathrm{MS} . \mathrm{m}^{-3} \mathrm{e} 21 \%$ menor que $100 \mathrm{~kg} \mathrm{MS.m}{ }^{-3}$. Esses valores de densidade são inferiores aos recomendados por Holmes \& Muck (1999), que citaram o limite mínimo de $225 \mathrm{~kg} \mathrm{MS} . \mathrm{m}^{-3}$ para que a densidade não seja fator de restrição na obtenção de silagem de qualidade satisfatória.

Crestana et al. (2000), trabalhando com silagens de capim-tanzânia com baixos teores de MS (20\%), verificaram que, à medida que havia redução do tamanho de partícula, ocorria significativa redução na produção de gases. Entretanto, nessas condições, houve aumento compensatório da produção de efluentes, mantendo-se inalteradas as perdas totais (em torno de 27\%). Segundo Igarasi (2002), as perdas por gases foram menores no inverno (3,5\% da MS vs $7,3 \%$ da MS no verão) em silagens de capim-tanzânia não tratadas com aditivos para elevação do teor de MS.

Bernardes et al. (2003), estudando a produção de efluente em silagens de capim-marandu produzidas com compactação de $900 \mathrm{~kg} \cdot \mathrm{m}^{-3}$ e inclusão de 0,5 e $10 \%$ de polpa cítrica peletizada, observaram que o escoamento de líquido (109, 71 e 17 L.t $^{-1}$ de silagem, respectivamente) ocorreu durante os cinco primeiros dias de ensilagem, evidenciando a grande quantidade de efluente produzido durante a ensilagem de gramíneas tropicais sem o uso de aditivo.

O objetivo neste trabalho foi estudar silagens de capimmarandu (Brachiaria brizantha) produzidas com quatro pressões de compactação durante a ensilagem.

\section{Material e Métodos}

Para uniformização da área utilizada, foi realizado o corte de rebaixamento e toda a forragem foi retirada do local. Em seguida, foi feita uma aplicação de $150 \mathrm{~kg}$ de uréia/ha no mês de fevereiro de 2004. A Brachiaria brizantha $\mathrm{cv}$. Marandu foi colhida no dia 23 de abril de 2004, quando o capim apresentava 60 dias de crescimento vegetativo (32\% de MS), utilizando-se máquina colhedeira de forragem $\left(\right.$ Casale ${ }^{\circledR}$ modelo CFC $\left.180 \mathrm{AP}\right)$ regulada para corte a $15 \mathrm{~cm}$ do solo.

O tamanho de partículas foi estimado por meio da ponderação da proporção de retenção do capim em cada uma das peneiras. Foram consideradas as proporções do material retido em abertura superior a $31,7 \mathrm{~mm}$ e entre 31,7 e 15,$9 ; 15,9$ e 12,$7 ; 12,7$ e 9,$5 ; 9,5$ e 7,$9 ;$ e 7,9 e $6,4 \mathrm{~mm}$, respectivamente.

O delineamento experimental utilizado foi o inteiramente casualizado com quatro repetições (pressões de compactação: $100 ; 120 ; 140 \mathrm{e} 160 \mathrm{~kg} \mathrm{MS} \cdot \mathrm{m}^{-3}$ ). Os dados relativos à produção de gás foram analisados utilizando-se o esquema de medidas repetidas no tempo.

Para confecção dos 16 silos experimentais, foram utilizados baldes de plástico (capacidade de 7 L) com tampas apropriadas para garantir vedação adequada. Na parte inferior dos baldes, foram adicionados em torno de $3 \mathrm{~kg}$ (2 L) de areia fina e seca e logo acima foi colocada uma tela protetora para impedir o contato da areia com a forragem e permitir a medida quantitativa do efluente produzido. $\mathrm{Na}$ 
extremidade superior de cada silo, foi instalada uma válvula do tipo "Bunsen" para escape dos gases produzidos, a fim de que as perdas de MS decorrentes do processo fermentativo fossem quantificadas gravimetricamente.

A forragem foi compactada por meio de bastões de ferro para acomodação de camadas de aproximadamente $10 \mathrm{~cm}$ de espessura. Com a acomodação final da forragem, os silos foram fechados e vedados com fitas plásticas adesivas para evitar a entrada de ar. Em seguida, foram pesados e armazenados em local protegido, sendo mantidos em temperatura ambiente.

O teor de MS foi determinado no momento da ensilagem para cálculo das densidades propostas em quilograma de MS utilizando-se a metodologia de secagem em microondas proposta por Pastorini et al. (2002).

Durante o período de fermentação (56 dias), em cada tratamento, foi avaliada a produção de gás e de efluente. As perdas por gases ao longo da fermentação (4으, $7^{\circ}, 14^{\circ}$, 28 , 56 - dias) foram calculadas como o peso do balde cheio no dia subtraído do peso observado no fechamento e expressas como a porcentagem da massa de forragem seca acondicionada nos silos.

Para estimar a quantidade de efluente produzida, após a retirada de toda silagem, a areia colocada no fundo do silo foi quantificada e de seu peso foi subtraído o valor original da areia antes do enchimento dos silos. A determinação da recuperação da MS foi obtida pelo quociente entre a quantidade recuperada dos baldes (abertura) e a quantidade inicialmente acondicionada nos baldes (fechamento) e expressa em porcentagem.

Após 56 dias de fermentação, os silos foram abertos e todo o seu conteúdo foi despejado sobre uma bacia plástica. O material foi homogeneizado e dividido em duas frações. A primeira foi utilizada para determinação dos teores de MS e PB, conforme a AOAC (1980), e das concentrações de FDN e FDA pelo método seqüencial, segundo técnicas descritas por Robertson \& Van Soest (1981). Para determinação dos teores de celulose, utilizou-se ácido sulfúrico a $72 \%$ (Van Soest, 1994). Os teores de hemicelulose foram calculados pela diferença entre FDN e FDA e os de lignina, pela diferença entre FDA e celulose. Uma nova análise de FDN e FDA foi realizada para, a partir desses resíduos, serem feitas as análises de NIDN e NIDA e determinada a fração B3, calculada como a diferença entre NIDN e NIDA. A digestibilidade verdadeira in vitro da MS (DIVMS) foi estimada conforme metodologia descrita por Silva \& Queiroz (2002). A segunda porção foi processada em liquidificador, segundo metodologia descrita por Kung Jr. et al. (1984), para obtenção do extrato aquoso, utilizado para determinação dos teores de nitrogênio amoniacal $\left(\mathrm{N}-\mathrm{NH}_{3}\right)$, segundo AOAC (1980), e do pH utilizando-se potenciômetro (Silva \& Queiroz, 2002).

Os dados foram analisados por meio do Programa de Análises Estatísticas do $\mathrm{SAS}^{\circledR}(\mathrm{SAS}, 1985)$, pelo procedimento GLM, e as médias, comparadas pelo teste Tukey a 5\% de significância. Quando necessária, a exploração das tendências foi acompanhada da declaração do nível de significância observado.

\section{Resultados e Discussão}

As densidades obtidas neste trabalho foram de 97,4; 118,$6 ; 139,2 ; 164,0 \mathrm{~kg} \mathrm{MS} . \mathrm{m}^{-3}$, para as pressões de compactação de 100; $120 ; 140$ e $160 \mathrm{~kg} \mathrm{MS} . \mathrm{m}^{-3}$, respectivamente.

A mensuração do tamanho de partícula da forragem a ser ensilada é importante, pois constitui fator que influencia diretamente na compactação durante a ensilagem e, conseqüentemente, no processo fermentativo (Muck et al., 2003). Após o corte da gramínea, efetuou-se a estratificação do material colhido, de modo que aproximadamente $72 \%$ das partículas eram maiores que $31,7 \mathrm{~mm}$, o que constituiu desvantagem sob o aspecto da compactação, pois impossibilitou a obtenção de maior densidade da massa ensilada.

Holmes \& Muck (1999) relataram que, para obtenção de silagem de boa qualidade, a pressão de compactação no silo deve ser de no mínimo $225 \mathrm{~kg} \mathrm{MS.m}{ }^{-3}$. Entretanto, neste experimento, considerando as características da forragem ensilada (tamanho da partícula e teor de MS), na silagem produzida com maior pressão de compactação, obteve-se o valor de $164,0 \mathrm{~kg} \mathrm{MS} . \mathrm{m}^{-3}$. Em experimento realizado por Igarasi (2002), silagens de capim-tanzânia apresentaram densidade de $150 \mathrm{~kg} \mathrm{MS} . \mathrm{m}^{-3}$, o que determinou características fermentativas satisfatórias.

Como pode ser observado na Figura 1, houve efeito exponencial das pressões de compactação nos valores médios de produção de gases ao longo do período fermentativo. Grande parte desta produção ocorreu no início da fermentação ( $4^{\circ}$ e 70 dia), observando-se que a produção de gases diminuiu com o passar do período fermentativo.

Verificou-se efeito $(\mathrm{P}<0,01)$ das densidades na produção total de gases (Tabela 1), que variou de 5,2 $\left(140 \mathrm{~kg} \mathrm{MS} . \mathrm{m}^{-3}\right)$ a $12,8 \%\left(120 \mathrm{~kg} \mathrm{MS} . \mathrm{m}^{-3}\right)$, observando-se que a maior intensidade de produção de gases ocorreu nas silagens produzidas com menores densidades (100 e $120 \mathrm{~kg} \mathrm{MS} . \mathrm{m}^{-3}$ ), o que pode ter sido ocasionado pelo ambiente e, conseqüentemente, pelo tipo de fermentação ocorrido, pois, segundo McDonald et al. (1991), maiores produções de gases estão associadas à presença de bactérias heterofermentativas e enterobactérias, destacando-se 


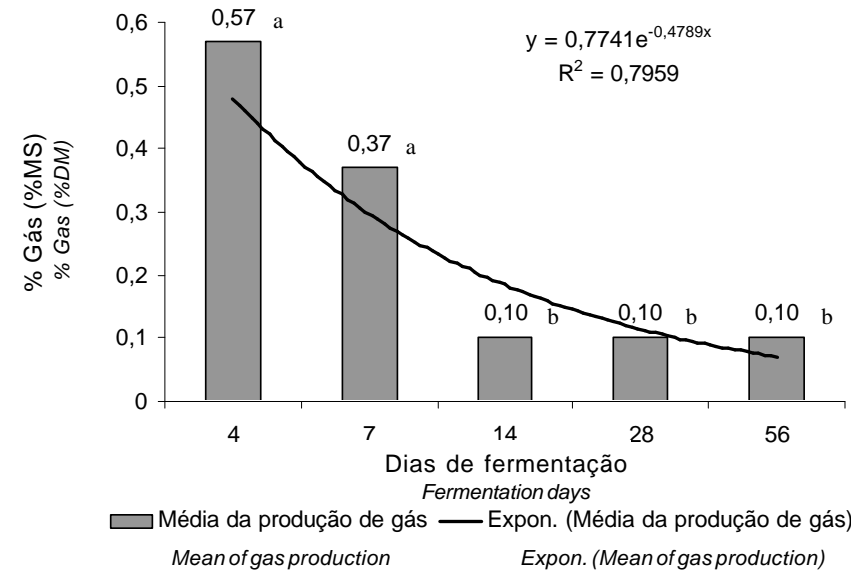

Figura 1 - Produção de gases ao longo do período fermentativo. Figure 1 - Means gas production intensity throughout the fermentative period.

Médias seguidas de mesma letra não diferem $(P>0,05)$ pelo teste Tukey.

Means followed by the same letter did not differ $(P>0.05)$ by Tukey test.

que a fermentação butírica é ocasionada por bactérias do gênero Clostridium.

O efluente das silagens apresenta grande quantidade de compostos orgânicos, como açúcares, ácidos orgânicos, proteínas e outros componentes, constituindo-se uma das formas de perdas do valor nutritivo durante a conservação da forragem (McDonald et al., 1991). Não houve efeito $(\mathrm{P}>0,05)$ das pressões de compactação sobre a produção de efluente (Tabela 1). A baixa produção verificada pode ter sido ocasionada pelo teor de MS da forragem no momento do corte. O efeito do teor de água na produção de efluente é amplamente citado na literatura. Diversos autores estudaram leguminosas e gramíneas e observaram diminuição na produção à medida que o teor de MS aumentou (Jones et al., 1990; Reynolds \& Willians, 1995; Jones \& Jones, 1995; Fransen \& Strubi, 1998; Haigh, 1999; Loures et al., 2005).

Apesar de os valores da produção de efluente não terem diferido $(\mathrm{P}>0,05)$, verificou-se crescente aumento na quantidade produzida com o aumento da densidade, o que está de acordo com os resultados obtidos por Loures et al. (2003), que verificaram aumento na produção de efluente quando intensificaram o grau de compactação da forragem.

À medida que aumentou a pressão de compactação das silagens (140 e $160 \mathrm{~kg} \mathrm{MS.m}{ }^{-3}$ ), os teores de MS mantiveram-se praticamente estáveis em relação aos encontrados na forragem no momento da ensilagem (Tabela 1), contrastando com os resultados obtidos nas mais baixas

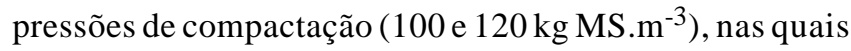
houve relativo aumento no teor de MS, justificado pela maior produção de gases nas silagens de densidades inferiores.

$\mathrm{O} \mathrm{pH}$ de um alimento é um dos principais fatores capazes de determinar o crescimento e a sobrevivência dos microrganismos presentes, além de ser empregado como parâmetro na qualificação do processo de ensilagem. Os resultados referentes aos valores de $\mathrm{pH}$ são apresentados na Tabela 1. Houve efeito $(\mathrm{P}<0,05)$ das pressões de compactação, podendo-se observar que os valores de $\mathrm{pH}$

Tabela 1 - Perdas por gases, produção de efluente, valores de $\mathrm{MS}, \mathrm{pH}$, nitrogênio amoniacal $\left(\mathrm{N}-\mathrm{NH}_{3}\right)$, recuperação de $\mathrm{MS}$ (REC MS) e digestibilidade in vitro da MS (DIVMS) de silagens de capim-marandu no momento de abertura dos silos

Table 1 - Gas losses, effluent production, $\mathrm{DM}, \mathrm{pH}$, ammoniac nitrogen $\left(\mathrm{N}-\mathrm{NH}_{3}\right), \mathrm{DM}$ recovery $(\mathrm{DMR})$ and in vitro DM digestibility of marandugrass at the silos opening

\begin{tabular}{|c|c|c|c|c|c|c|c|c|}
\hline \multirow[b]{2}{*}{$\begin{array}{l}\text { Item } \\
\text { Item }\end{array}$} & \multicolumn{4}{|c|}{$\begin{array}{c}\text { Pressão de compactação }\left(\mathrm{kg} \mathrm{MS} \cdot \mathrm{m}^{-3}\right) \\
\text { Compaction pressures }\left(\mathrm{kg} \text { DM. } \mathrm{m}^{-3}\right)\end{array}$} & \multirow[b]{2}{*}{$\begin{array}{l}\text { Média } \\
\text { Mean }\end{array}$} & \multirow[b]{2}{*}{$\operatorname{Pr}>F^{1}$} & \multirow[b]{2}{*}{$\mathrm{CV}^{2}$} & \multirow[b]{2}{*}{$\begin{array}{r}\mathrm{EPM}^{3} \\
\text { SEM }\end{array}$} \\
\hline & 100 & 120 & 140 & 160 & & & & \\
\hline $\begin{array}{l}\text { Gás, \% MS } \\
\text { Gas, \% DM }\end{array}$ & $7,8^{\mathrm{ab}}$ & $12,8^{\mathrm{a}}$ & $5,2^{\mathrm{b}}$ & $6,0^{\mathrm{b}}$ & 8,0 & $* *$ & 34,1 & 1,4 \\
\hline $\begin{array}{l}\text { Efluente, } \mathrm{kg} / \mathrm{t} \mathrm{MV} \\
\text { Effluent, } \mathrm{kg} / \mathrm{t} \text { fresh matter }\end{array}$ & $2,2^{\mathrm{a}}$ & $4,9^{\mathrm{a}}$ & $7,6^{\mathrm{a}}$ & $9,8^{\mathrm{a}}$ & 6,1 & 0,4 & 105,4 & 3,2 \\
\hline $\begin{array}{l}\text { MS, \% } \\
D M, \%\end{array}$ & $27,8^{\mathrm{b}}$ & $28,4^{\mathrm{b}}$ & $32,7^{\mathrm{a}}$ & $31,2^{\mathrm{ab}}$ & 30,0 & $* *$ & 5,4 & 0,8 \\
\hline $\mathrm{pH}$ & $6,8^{\mathrm{a}}$ & $6,8^{\mathrm{a}}$ & $4,9^{b}$ & $4,8^{b}$ & 5,8 & $*$ & 16,1 & 0,5 \\
\hline $\begin{array}{l}\mathrm{N}-\mathrm{NH}_{3}, \% \text { N-total } \\
\mathrm{N}-\mathrm{NH}_{3}, \% \text { Total N }\end{array}$ & $9,5^{\mathrm{a}}$ & $10,4^{\mathrm{a}}$ & $11,5^{\mathrm{a}}$ & $9,6^{\mathrm{a}}$ & 10,2 & 0,8 & 33,7 & 1,7 \\
\hline $\begin{array}{l}\text { REC MS, \% } \\
D M R, \%\end{array}$ & $83,1^{\mathrm{b}}$ & $83,5^{b}$ & $94,4^{\mathrm{a}}$ & $96,4^{\mathrm{a}}$ & 91,9 & $* *$ & 4,9 & 2,3 \\
\hline $\begin{array}{l}\text { DIVMS, \% } \\
\text { IVDMD, \% }\end{array}$ & $55,7^{\mathrm{b}}$ & $52,8^{\mathrm{b}}$ & $58,6^{\mathrm{ab}}$ & $62,4^{\mathrm{a}}$ & 57,4 & $*$ & 6,4 & 1,8 \\
\hline
\end{tabular}

Médias seguidas da mesma letra não diferem $(\mathrm{P}>0,05) ;{ }^{1} \mathrm{Pr}>\mathrm{F}$ : valor de $\mathrm{P},{ }^{2} \mathrm{CV}$ : coeficiente de variação, ${ }^{3} \mathrm{EPM}$ : erro-padrão da média; ${ }^{*} \mathrm{P}<0,05 ;{ }^{*} \mathrm{P}<0,01$; D1: densidade de $100 \mathrm{~kg} \mathrm{MS} . \mathrm{m}^{-3}$, D2: densidade de $120 \mathrm{~kg} \mathrm{MS} \cdot \mathrm{m}^{-3}$, D3: densidade de $140 \mathrm{~kg} \mathrm{MS} . \mathrm{m}^{-3}$, D4: densidade de $160 \mathrm{~kg} \mathrm{MS} . \mathrm{m}^{-3}$.

Means followed by the same letter do not differ $(P>0.05) ;{ }^{1} \mathrm{Pr}>\mathrm{F}: \mathrm{P}$ value, ${ }^{2} \mathrm{CV}$ : coefficient of variation, ${ }^{3} \mathrm{SEM}$ : standard error of mean, ${ }^{*} P<0.05 ;{ }^{* *} P<0.01 ; D 1:$ density of $100 \mathrm{~kg}$ DM. $\mathrm{m}^{-3}$, D2: density of $120 \mathrm{~kg} \mathrm{DM} \cdot \mathrm{m}^{-3}, \mathrm{D} 3:$ density of $140 \mathrm{~kg} D M . \mathrm{m}^{-3}, \mathrm{D} 4:$ density of $160 \mathrm{~kg} \mathrm{DM} \cdot \mathrm{m}^{-3}$ 
das silagens mais bem compactadas (140 e $\left.160 \mathrm{~kg} \mathrm{MS.m}{ }^{-3}\right)$ reduziram em relação aos obtidos com menor compactação (100 e $120 \mathrm{~kg} \mathrm{MS} . \mathrm{m}^{-3}$ ), ou seja, a maior compactação promoveu melhor ambiente para as bactérias produtoras de ácido lático.

Valores de pH de 3,8 a 4,2 são esperados em uma silagem bem conservada, porém, é importante ressaltar que o $\mathrm{pH}$ de estabilidade, juntamente com a velocidade com que se declina durante o processo fermentativo, pode determinar os tipos de microrganismos capazes de crescer e dominar o ambiente (McDonald et al., 1991). De acordo com os resultados obtidos, pode-se inferir que, nas silagens produzidas com maior pressão de compactação (140 e 160 kg MS.m ${ }^{-3}$ ), o ambiente foi propício ao crescimento de microrganismos desejáveis, ao contrário do ocorrido nas silagens com 100 e $120 \mathrm{~kg} \mathrm{MS} . \mathrm{m}^{-3}$, nas quais o ambiente favoreceu a atividade de microrganismos indesejáveis.

O teor de nitrogênio amoniacal $\left(\mathrm{N}-\mathrm{NH}_{3}\right)$, em comparação ao de nitrogênio total, é um dos parâmetros que designa a qualidade do processo fermentativo. Uma das principais alterações na ensilagem é o aumento do nitrogênio, que é afetado pela ação de microrganismos. Segundo McGechan (1989), maiores teores de $\mathrm{N}-\mathrm{NH}_{3}$ indicam maior intensidade de proteólise, principalmente pela degradação de aminoácidos por clostrídeos proteolíticos. Não houve efeito $(\mathrm{P}>0,05)$ na produção de $\mathrm{N}-\mathrm{NH}_{3}$ (Tabela 1) nos diferentes tratamentos, ressaltando que os resultados obtidos foram próximos aos considerados satisfatórios na conservação de gramíneas tropicais (Benacchio, 1965).

Segundo Woolford (1984) e McDonald et al. (1991), a proteólise se estende durante a fermentação quando não ocorrem condições ácidas suficientes para que os microrganismos indesejáveis sejam inibidos. Possivelmente, nas silagens produzidas com maiores pressões de compactação, a produção de amônia pode ser decorrente do baixo teor de carboidratos solúveis característico do alimento, em que as bactérias ácido-láticas estariam utilizando aminoácidos como fonte de energia para crescimento e metabolismo. De acordo com McGechan (1989) e McDonald et al. (1991), as bactérias ácido-láticas normalmente não são proteolíticas, mas agem como tais quando tem limitado teor de nutrientes ou baixo poder de síntese de aminoácidos, sendo necessário um suprimento extra. Sua habilidade em fermentar aminoácidos é restrita a serina e arginina e os produtos obtidos de arginina são ornitina, $\mathrm{CO}_{2}$ e $\mathrm{NH}_{3}$ e os da serina, acetona, $\mathrm{CO}_{2}$ e $\mathrm{NH}_{3}$.

As silagens produzidas com maiores pressões de compactação (140 e $160 \mathrm{~kg} \mathrm{MS.m}{ }^{-3}$ ) apresentaram os maiores valores de recuperação de MS (Tabela 1), com média de $95,4 \%$, enquanto, na menor pressão de compactação, a recuperação foi de $83,1 \%$. Esse maior valor de recuperação de MS pode ter sido influenciado pela produção de gases, pois as perdas por gases foram menores nas silagens sob maiores pressões de compactação. Os valores, no entanto, foram pouco expressivos na geração de efluentes. Mari (2003), avaliando o intervalo de cortes em diferentes estações do ano em silagem de capim-marandu, verificou que a recuperação de MS é intensamente prejudicada pelo aumento na produção de gases na fermentação, sendo pouco notória a produção de efluentes.

A digestibilidade in vitro da MS foi maior nas silagens com maior densidade (Tabela 1), seguida das silagens produzidas com pressões de compactação de 140, 100 e $120 \mathrm{~kg} \mathrm{MS}^{-3}{ }^{-3}$, indicando, portanto, efeito significativo das pressões de compactação $(\mathrm{P}<0,05)$. A amplitude dos valores do coeficiente de DIVMS foi de 52,8 (120 kg MS.m $\left.{ }^{-3}\right)$ a $62,4 \%\left(160 \mathrm{~kg} \mathrm{MS} \cdot \mathrm{m}^{-3}\right)$. Possivelmente, os maiores valores

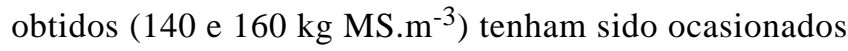
pela menor concentração de FDN, FDA e celulose nessas silagens (Tabela 3). Além disso, o ambiente propiciou o perfil de fermentação, diminuindo a proteólise pela queda mais acentuada do $\mathrm{pH}$ e pelas menores perdas de gases que consomem principalmente a fração mais digestível.

Os resultados referentes aos teores de PB das silagens de capim-marandu são apresentados na Tabela 2. Não houve significância nos teores de $\mathrm{PB}(\mathrm{P}>0,05)$, que foram praticamente mantidos iguais ao da forragem no momento da ensilagem. Do total do nitrogênio presente em forragens, 75 a 90\% estão na forma de proteínas - o restante é encontrado principalmente como peptídeos, aminoácidos livres, aminas, nucleotídeos, clorofila e nitratos. Nas silagens, a extensão da degradação da proteína verdadeira varia com a espécie da planta, com a taxa de mudança do $\mathrm{pH}$, com o conteúdo de MS e com a temperatura (McDonald et al., 1991).

Segundo Cherney (2000), a simples determinação da concentração de PB é inadequada para qualificar a proteína presente na forragem. O superaquecimento na presença de carboidratos solúveis e frações nitrogenadas produz os polímeros de Maillard, o que aumenta os teores de nitrogênio ligado à parede celular.

Segundo Balsalobre et al. (2001), o NIDN tem ampla variação entre análises bromatológicas, sendo encontrados valores de 25 a $70 \%$ e maior freqüência na faixa de 40 a $60 \%$ do N-total. Nussio et al. (2002) relataram que, na forragem fresca de gramíneas tropicais, uma considerável porção da fração N-total está ligada à parede celular e esses valores são considerados elevados e compatíveis com forragens submetidas ao superaquecimento, entretanto, esses autores 
Tabela 2 - Valores médios de MS, PB, NIDN, NIDA e fração B3 das silagens de capim-marandu no momento de abertura dos silos Table 2 - Average DM, CP, NDIN, ADIN, and B3 fraction of marandugrass at the silos opening

\begin{tabular}{|c|c|c|c|c|c|c|c|c|}
\hline \multirow[b]{2}{*}{$\begin{array}{l}\text { Item } \\
\text { Item }\end{array}$} & \multicolumn{4}{|c|}{$\begin{array}{c}\text { Pressão de compactação }\left(\mathrm{kg} \mathrm{MS} . \mathrm{m}^{-3}\right) \\
\text { Compaction pressures }\left(\mathrm{kg} D M . \mathrm{m}^{-3}\right)\end{array}$} & \multirow[b]{2}{*}{$\begin{array}{l}\text { Média } \\
\text { Mean }\end{array}$} & \multirow[b]{2}{*}{$\operatorname{Pr}>F^{1}$} & \multirow[b]{2}{*}{$\mathrm{CV}^{2}$} & \multirow[b]{2}{*}{$\begin{array}{c}\mathrm{EPM}^{3} \\
S E M\end{array}$} \\
\hline & 100 & 120 & 140 & 160 & & & & \\
\hline $\begin{array}{l}\mathrm{PB}, \% \mathrm{MS} \\
C P, \% D M\end{array}$ & $5,0^{\mathrm{a}}$ & $5,0^{\mathrm{a}}$ & $4,5^{\mathrm{a}}$ & $4,7^{\mathrm{a}}$ & 4,8 & 0,4 & 9,9 & 0,2 \\
\hline $\begin{array}{l}\text { NIDN, \% N-total } \\
\text { NDIN, \% Total N }\end{array}$ & $34,3^{\mathrm{a}}$ & $29,5^{\mathrm{ab}}$ & $22,9^{\mathrm{bc}}$ & $20,4^{\mathrm{c}}$ & 26,8 & $* *$ & 13,5 & 1,8 \\
\hline $\begin{array}{l}\text { N-FDA, \% N-total } \\
\text { ADIN, \% Total N }\end{array}$ & $18,2^{\mathrm{a}}$ & $21,5^{\mathrm{a}}$ & $17,5^{\mathrm{a}}$ & $15,1^{\mathrm{a}}$ & 18,1 & 0,1 & 16,3 & 1,5 \\
\hline $\begin{array}{l}\text { B3, \% N-total } \\
\text { B3, \% Total N }\end{array}$ & $16,0^{\mathrm{a}}$ & $8,0^{\mathrm{b}}$ & $5,4^{\mathrm{b}}$ & $5,3^{\mathrm{b}}$ & 8,7 & $* *$ & 27,2 & 1,2 \\
\hline
\end{tabular}

Médias seguidas da mesma letra não diferem $(P>0,05)$ pelo teste Tukey; ${ }^{1} \mathrm{Pr}>\mathrm{F}$ : valor de $\mathrm{P},{ }^{2} \mathrm{CV}$ : coeficiente de variação, ${ }^{3} \mathrm{EPM}$ : erro-padrão da média ${ }^{\star} \mathrm{P}<0,05 ;{ }^{\star \star} \mathrm{P}<0,01$; D1: densidade de $100 \mathrm{~kg} \mathrm{MS} \cdot \mathrm{m}^{-3}$, D2: densidade de $120 \mathrm{~kg} \mathrm{MS} \cdot \mathrm{m}^{-3}$, D3: densidade de $140 \mathrm{~kg} \mathrm{MS} \cdot \mathrm{m}^{-3}, \mathrm{D} 4:$ densidade de $160 \mathrm{~kg}$ MS.m ${ }^{-3}$. Means followed by the same letter do not differ $(P>0.05) ;{ }^{1} \mathrm{Pr}>\mathrm{F}: \mathrm{P}$ value, ${ }^{2} \mathrm{CV}$ : coefficient of variation, ${ }^{3} \mathrm{SEM}$ : standard error of the mean, ${ }^{\star} P<0.05 ;{ }^{* *} P<0.01 ; D 1$ : density of $100 \mathrm{~kg} D \mathrm{M} . \mathrm{m}^{-3}$, D2: density of $120 \mathrm{~kg} \mathrm{DM} . \mathrm{m}^{-3}, \mathrm{D} 3:$ density of $140 \mathrm{~kg} \mathrm{DM} . \mathrm{m}^{-3}, \mathrm{D} 4:$ density of $160 \mathrm{~kg} \mathrm{DM} . \mathrm{m}^{-3}$.

destacaram que, nesse caso, este tipo de ligação é de ocorrência natural.

À medida que aumentou o grau de compactação da forragem, verificou-se diminuição $(\mathrm{P}<0,01)$ nos valores de NIDN (Tabela 2), o que pode estar relacionado à degradação da fração B3, mais pronunciada nas pressões de compactação de 140 e 160 kg MS.m ${ }^{-3}$, que proporcionaram melhores condições fermentativas. No entanto, não houve efeito $(\mathrm{P}>0,05)$ das pressões de compactação sobre os valores de NIDA (Tabela 2), que foram semelhantes ao da forragem original.

Verificou-se efeito das pressões de compactação $(\mathrm{P}<0,01)$ sobre os valores da fração B3 (Tabela 2), estimada pela subtração entre as frações de NIDN e NIDA. Nas maiores pressões de compactação (140 e 160 kg MS.m ${ }^{-3}$ ), a concentração da fração foi mais reduzida que nas den-

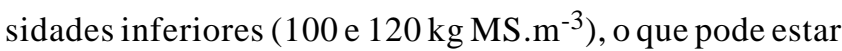
relacionado à redução nos teores de NIDN e na atividade proteolítica, pois, segundo Sniffen et al. (1992), a fração B3 tem significativa importância nas reações proteolíticas durante a ensilagem, visto que aumentos nos valores de $\mathrm{N}$ amoniacal podem ser relativos à decomposição da fração protéica.

Houve efeito $(\mathrm{P}<0,01)$ das pressões de compactação sobre o teor de FDN (Tabela 3). Os menores valores foram

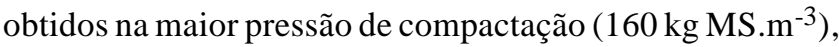

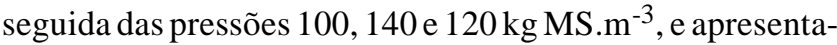
ram redução em relação ao valor da forragem no momento da ensilagem, sendo verificada diminuição mais acentuada na

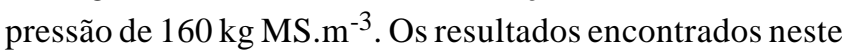
trabalho foram superiores aos registrados por Bernardes et al. (2005), que verificaram teores médios de FDN de 75,2\%, e por Bergamaschine et al. (2006), que observaram teor de FDN de 73,0\%, ambos em silagens de capim-marandu.
As pressões de compactação tiveram efeito nos teores de FDA $(\mathrm{P}<0,01)$, que foram menores na maior pressão de compactação, seguida das pressões 100, 140 e 120 kg MS.m ${ }^{-3}$ (Tabela 3), possivelmente porque, na maior pressão de compactação, a atividade de enzimas que degradam a celulose ocasionou maior redução no teor de FDA.

No entanto, as pressões de compactação não tiveram efeito efeito sobre os teores de hemicelulose. De acordo com McDonald et al. (1991), a ausência de efeito das pressões de compactação sobre os valores de hemicelulose ( $\mathrm{P}>0,05)$ pode ser justificada pela hidrólise ácida da hemicelulose causada por ácidos orgânicos produzidos durante a fermentação, bem como pela ação de hemicelulases provenientes da forragem e de microrganismos. Segundo esses autores, a quantidade desses ácidos durante a fermentação é geralmente superior à disponibilidade de carboidratos solúveis, sugerindo que outros substratos, como proteínas, aminoácidos, ácido lático e, principalmente carboidratos fibrosos, podem ser utilizados como suprimento para os microrganismos.

Nesta pesquisa, verificou-se efeito $(\mathrm{P}<0,01)$ das pressões de compactação sobre os teores de celulose nas silagens (Tabela 3). O maior valor foi obtido com pressão

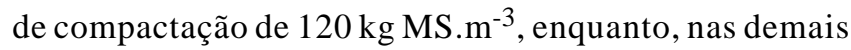
pressões de compactação, os valores não diferiram entre si. Os teores de celulose obtidos nesse experimento se assemelharam aos descritos por Mari (2003), que, trabalhando com silagens de capim-marandu colhido aos 60 dias de crescimento vegetativo, encontrou teor de $35,6 \%$ de celulose. Van Soest (1994) relatou que a fração representada pela celulose se mantém estável durante a fermentação no interior do silo, o que foi confirmado neste estudo (Tabela 3), pois os teores desse nutriente não apresentaram grande variação. 
Tabela 3 - Valores nutricionais de silagens de capim-marandu no momento da abertura dos silos Table 3 - Values of NDF, ADF, HEM, CEL, and LIG of marandugrass at the silos opening

\begin{tabular}{|c|c|c|c|c|c|c|c|c|}
\hline \multirow[b]{2}{*}{ Item } & \multicolumn{4}{|c|}{$\begin{array}{c}\text { Pressão de compactação }\left(\mathrm{kg} \mathrm{MS} . \mathrm{m}^{-3}\right) \\
\text { Compaction pressures }\left(\mathrm{kg} D M . \mathrm{m}^{-3}\right)\end{array}$} & \multirow[b]{2}{*}{ Média } & \multirow[b]{2}{*}{$\operatorname{Pr}>F^{1}$} & \multirow[b]{2}{*}{$\mathrm{CV}^{2}$} & \multirow[b]{2}{*}{ EPM } \\
\hline & 100 & 120 & 140 & 160 & & & & \\
\hline $\begin{array}{l}\text { FDN, \% MS } \\
N D F, \% D M\end{array}$ & $78,1^{b}$ & $80,0^{\mathrm{a}}$ & $78,3^{\mathrm{ab}}$ & $76,2^{\mathrm{c}}$ & 78,1 & $* *$ & 1,1 & 0,4 \\
\hline $\begin{array}{l}\text { FDA, \% MS } \\
A D F, \% D M\end{array}$ & $40,3^{\mathrm{ab}}$ & $42,9^{\mathrm{a}}$ & $40,5^{\mathrm{ab}}$ & $37,9^{\mathrm{b}}$ & 40,4 & $* *$ & 3,3 & 0,7 \\
\hline $\begin{array}{l}\text { HEM, \% MS } \\
\text { HEM, \% DM }\end{array}$ & $37,7^{\mathrm{a}}$ & $37,1^{\mathrm{a}}$ & $37,8^{a}$ & $38,3^{\mathrm{a}}$ & 37,8 & 0,5 & 2,8 & 0,5 \\
\hline $\begin{array}{l}\text { CEL, \% MS } \\
C E L, \% D M\end{array}$ & $33,9^{b}$ & $36,5^{\mathrm{a}}$ & $33,6^{b}$ & $32,4^{b}$ & 34,1 & $* *$ & 3,5 & 0,6 \\
\hline $\begin{array}{l}\text { LIG, \% MS } \\
L I G, \% D M\end{array}$ & $6,5^{\mathrm{a}}$ & $6,4^{\mathrm{a}}$ & $6,9^{\mathrm{a}}$ & $5,5^{\mathrm{a}}$ & 6,3 & 0,1 & 12,5 & 0,4 \\
\hline
\end{tabular}

Médias seguidas de mesma letra não diferem $(\mathrm{P}>0,05) ;{ }^{1} \mathrm{Pr}>\mathrm{F}$ : valor de $\mathrm{P},{ }^{2} \mathrm{CV}$ : coeficiente de variação, ${ }^{3} \mathrm{EPM}$ : erro-padrão da média; ${ }^{*} \mathrm{P}<0,05 ;{ }^{* \star} \mathrm{P}<0,01$; D1: densidade de $100 \mathrm{~kg} \mathrm{MS} \cdot \mathrm{m}^{-3}$, D2: densidade de $120 \mathrm{~kg} \mathrm{MS} \cdot \mathrm{m}^{-3}$, D3: densidade de $140 \mathrm{~kg} \mathrm{MS}$. $\mathrm{m}^{-3}$, D4: densidade de 160 kg MS. ${ }^{-3}$

Means followed by the same letter do not differ $(P>0.05) ;{ }^{1} P r>F: P$ value, ${ }^{2} \mathrm{CV}$ : coefficient of variation, ${ }^{3}$ SEM: standard error of mean, ${ }^{*} P<0.05 ;{ }^{* *} P<0.01 ; D 1:$ density of $100 \mathrm{~kg} D M . \mathrm{m}^{-3}, \mathrm{D} 2:$ density of $120 \mathrm{~kg} D M . \mathrm{m}^{-3}, \mathrm{D} 3:$ density of $140 \mathrm{~kg} \mathrm{DM} . \mathrm{m}^{-3}, \mathrm{D} 4:$ density of $160 \mathrm{kgDM} . \mathrm{m}^{-3}$.

Assim como a celulose, a lignina se mantém estável durante a fermentação da forragem. Parte dessas frações é degradada apenas quando há presença de fungos portadores de ligninase. Neste estudo, não houve efeito das pressões de compactação $(\mathrm{P}>0,05)$ sobre os teores de lignina (Tabela 3). Os valores foram superiores aos encontrados por Mari (2003), de 4,0\%, em silagens de capim-marandu colhido aos 60 dias de crescimento vegetativo, e aos obtidos por Bernardes et al. (2005), de 4,9\% de lignina.

\section{Conclusões}

A elevação da densidade da massa no silo propicia processo fermentativo favorável, por promover a redução no $\mathrm{pH}$ e aumentar a taxa de recuperação de MS da silagem. As silagens de maior densidade apresentam melhor conservação, representada por maiores coeficientes de digestibilidade in vitro da MS. O aumento da pressão de compactação pode favorecer a ensilagem quando a forragem possui elevado tamanho de partícula.

\section{Agradecimento}

À Fundação de Amparo à Pesquisa do Estado de São Paulo, pelo apoio financeiro ao projeto e pela concessão de bolsas de estudo.

\section{Literatura Citada}

ASSOCIATION OF OFFICIAL AGRICULTURAL CHEMISTS AOAC. Official methods of analyses of the Association of Official analytical chemists. 13.ed. Washington: AOAC International, 1980. 1015p.
BALSALOBRE, M.A.A.; NUSSIO, L.G.; MARTHA JR.; G.B. Controle de perdas na produção de silagens de gramíneas tropicais. In: MATTOS, W.R.S. (Ed.) A produção animal na visão dos brasileiros. Piracicaba: Sociedade Brasileira de Zootecnia, 2001. p.890-911.

BENACCHIO, S. Niveles de melaza em silo experimental de milho criollo (Sorghum vulgare). Agronomia Tropical, v.14, n.4, p.651-658, 1965.

BERGAMASCHINE, A.F.; PASSIPIÉRI, M.; VERIANO FILHO, W.V. et al. Qualidade e valor nutritivo de silagens de capimmarandu (B. brizantha cv. Marandu) produzidas com aditivos ou forragem emurchecida. Revista Brasileira de Zootecnia, v.35, n.4, p.1454-1462, 2006.

BERNARDES, T.F.; REIS, R.A.; AMARAL, R.C. et al. Produção e composição do efluente das silagens de capim-Marandu (Brachiaria brizantha cv. Marandu) submetidas a inclusão de polpa cítrica peletizada In: REUNIÃO ANUAL DA SOCIEDADE BRASILEIRA DE ZOOTECNIA, 40., 2003, Santa Maria. Anais... Santa Maria: SBZ, 2003. (CD-ROM).

BERNARDES, T.F.; REIS, R.A.; MOREIRA, A.L. Fermentative and microbiological profile of Marandugrass ensiled with citrus pulp pellets. Scientia Agricola, v.62, n.3, p.214-220, 2005.

CHERNEY, D.J.R. Characterization of forages by chemical analysis. In: GIVENS, D.I.; OWEN, E.; AXFORD, R.F.E. et al. (Eds.) Forage evaluation in ruminant nutrition. New York: CABI Publishing, 2000. p.281-300.

CRESTANA, R.F.; AGUIAR, R.N.S.; NUSSIO, L.G. et al. Avaliação das perdas de silagem de capim Tanzânia (Panicum maximum Jacq. cv. Tanzânia) pré-secado ou com adição de polpa cítrica em três tamanhos de partícula. In: SIMPÓSIO INTERNACIONAL DE INICIAÇÃO CIENTÍFICA DA UNIVERSIDADE DE SÃO PAULO, 8., 2000, Piracicaba. Anais... Piracicaba: USP, 2000. (CD-ROM).

FRANSEN, S.C.; STRUBI, F.J. Relationship among absorbents and the reduction of grass silage effluent and silage quality. Journal of Dairy Science, v.81, p.2633-2644, 1998.

HAIGH, P.M. Effluent production from grass silages treated with additives and made in large-scale bunker silos. Grass and Forage Science, v.54, p.208-218, 1999.

HOLMES, B.J.; MUCK, R.E. Factors affecting bunker silos densities. Madison: University of Wisconsin, 1999. 7p.

IGARASI, M.S. Controle de perdas na ensilagem de capim Tanzânia (Panicum maximum Jacq. Cv. Tanzânia) sob os efeitos do teor de matéria seca, do tamanho de partícula, da estação do ano e da presença de inoculante microbiano. 
Piracicaba: Escola Superior de Agricultura "Luiz de Queiroz", 2002. 152p. Dissertação (Mestrado em Ciência Animal e Pastagens) - Escola Superior de Agricultura "Luiz de Queiroz", 2002.

JONES, D.I.H.; JONES, R.; MOSELEY, G. Effect of incorporating rolled barley in autumn cut ryegrass silage on effluent production, silage fermentation and cattle performance. Journal of Agricultural Science, v.115, p.399-408, 1990.

JONES, D.I.H.; JONES, R. The effect of crop caracteristics and ensiling methodology on grass silage effluent production. Journal of Agricultural Engineering Research, v.60, p.73-81, 1995 .

KUNG JR., L.; GRIEVE, D.B.; THOMAS, J.W. Added ammonia or microbial inoculant for fermentation and nitrogenous compounds of alfalfa ensiled at various percents of dry matter. Journal of Dairy Science, v.67, p.299-306, 1984.

LOURES, D.R.S.; GARCIA, R.; PEREIRA, O.G. et al. Características do efluente e composição químico-bromatológica da silagem de capim-elefante sob diferentes níveis de compactação. Revista Brasileira de Zootecnia, v.32, n.6, p.1851-1858, 2003 (supl.2).

LOURES, D.R.S.; NUSSIO, L.G.; PAZIANI, S.F. et al. Composição bromatológica e produção de efluente de silagens de capimTanzânia sob efeitos do emurchecimento, do tamanho de partícula e do uso de aditivos biológicos. Revista Brasileira de Zootecnia, v.34, n.3, p.723-735, 2005.

MARI, L.J. Intervalo entre cortes em capim Marandu (Brachiaria brizantha (Hochst. ex A. Rich.) Stapf cv. Marandu): produção, valor nutritivo e perdas associadas à fermentação da silagem. Piracicaba: Escola Superior de Agricultura "Luiz de Queiroz", 2003. 138p. Dissertação (Mestrado em Ciência Animal e Pastagens) - Escola Superior de Agricultura "Luiz de Queiroz", 2003.

McDONALD, P.J.; HENDERSON, A.R.; HERON, S.J.E. The biochemistry of silage. 2.ed. Mallow: Chalcombe Publications, 1991. 340p.

McGECHAN, M.B. A review of losses arising during conservation of grass forage: storage losses. Journal Agricultural Engineering Research, v.45, p.1-30, 1989.

MUCK, R.E.; MOSER, L.E.; PITT, R.E. Postharvest factors affecting ensiling. In: BUXTON, D.R.; MUCK, R.E.; HARRISON, J.H. (Eds). Silage science and technology. Madison: American Society of Agronomy, 2003. p.251-304.
NUSSIO, L.G.; PAZIANI, S.F.; NUSSIO, C.M.B. Ensilagem de capins tropicais. In: REUNIÃO ANUAL DA SOCIEDADE BRASILEIRA DE ZOOTECNIA, 39., 2002, Recife. Anais... Recife: Sociedade Brasileira de Zootecnia, 2002. p.60-99.

PASTORINI, L.H.; BACARIN, M.A.; ABREU, C.M. Secagem de material vegetal em forno de microondas para determinação de matéria seca e análises químicas. Ciência Agrotécnica, v.26, p.1252-1258, 2002.

REYNOLDS, A.M.; WILLIAMS, A.G. A model of silage consolidation and effluent flow. Journal of Agricultural Engineering Research, v.61, p.173-182, 1995.

REIS, R.A.; COAN, R.M. Produção e utilização de silagens de gramíneas. In: SIMPÓSIO GOIANO SOBRE MANEJO E NUTRIÇÃO DE BOVINOS. Anais... Goiânia: Colégio Brasileiro de Nutrição Animal, 2001. p.91-120.

ROBERTSON, J.B.; Van SOEST, P.J. The detergent system of analysis and its application to human foods. In: JAMES, W.P.T.; THEANDER, O. (Eds.) The analysis of dietary fiber in food. New York: Marcel Dekker, 1981. p.123-158.

RUPPEL, K.A.; PITT, R.E.; CHASE, L.E. et al. Bunker silo management and its relationship to forage preservation on dairy farms. Journal of Dairy Science, v.78, p.141-153, 1995.

STATISTICAL ANALYSES SYSTEM - SAS. The SAS system for Windows. version 6.12 Cary: 1985. (compact disc).

SILVA, D.J.; QUEIROZ, A.C. Análise de alimentos: métodos químicos e biológicos. 3.ed. Viçosa, MG: Editora UFV, 2002. $235 \mathrm{p}$.

SNIFEN, C.J.; O'CONNOR, J.D.; Van SOEST, P.J. et al. A net carbohydrate and protein system for evaluating cattle diets: II. Carbohydrate and protein availability. Journal of Animal Science, v.70, p.3562-3577, 1992.

Van SOEST, P.J. Nutritional ecology of the ruminants. 2.ed. Ithaca: Cornell University, 1994. 476p.

WOOLFORD, M.K. The silage fermentation. New York: Marcel Dekker, 1984. 350p. 